\title{
Pengolahan Buah Pisang Menjadi Pinangun (Pisang Nugget Donowangun) Sebagai Upaya Peningkatan Pendapatan Masyarakat Desa Donowangun
}

\author{
Natal kristiono ${ }^{1}$, Indri Astuti ${ }^{2}$, Fitri Hidayati ${ }^{3}$ \\ Universitas Negeri Semarang \\ *email: natalkristiono@mail.unnes.ac.id
}

\begin{abstract}
Donowangun Village, Talun District, has excellent plantation potential, one of the abundant commodities is banana. Banana fruit is a food material that has high economic value. The availability of bananas during the harvest season causes the price of bananas to decline. Of course, action needs to be taken so that prices do not fall too sharply. This problem condition is the basis of the Banana Fruit Processing Training activity to Pinangun (Banana Nugget Donowangun) in Donowangun Village. The purpose of this activity is to process bananas into processed products with high economic value, namely by making banana nuggets. The abundant availability of bananas certainly does not make it difficult for the surrounding community to later open a banana nugget business which has high economic value so that they have high hopes for increasing the market share of this banana fruit. In this activity the UNNES KKN team provided material on the future prospects of the nugget banana processing business. The next material is training on processing banana nuggets that are ready to be produced and have high selling value and proper packaging. The methods used are creative lectures, practice / demonstrations and discussions. The result of this activity is the increased insight and knowledge of PKK Donowangun Village women regarding banana processing. It is hoped that later it will motivate PKK women to create a home industry for banana nuggets.
\end{abstract}

Keywords: Processing, Panana fruit, Donowangun

\section{Pendahuluan}

Desa Donowangun Kecamatan Talun Kabupaten Pekalongan memiliki luas lahan pertanian cukup besar. Sebagian lahan pertanian tersebut digunakan warga untuk menanam pohon durian dan pohon pisang. Masyarakat Desa Donowangun hampir semuanya menanam pohon pisang dikebun dengan alasan pohon pisang cocok di jenis tanah apapun dan penanaman serta perawatannya tergolong mudah dan tidak membutuhkan 
biaya lebih. Selain itu, pisang juga banyak digemari masyarakat sekitar. Ratarata pisang yangditanam adalah pisang belitung. Tekstur pisang belitung adalah lembut dan rasanya pun manis.

Berdasarkan paparan kepala Desa Donowangun dan beberapa masyarakat yang bekerja sebagai petani, kondisi yang dihadapi petani saat ini adalah kurangnya sumber daya manusia dalam pengolahan hasil pertanian. Hal ini berdampak pada minimnya inisiatif petani dalam pemasaran hasil pertanian. Hingga saat ini masyarakat masih tergantung pada tengkulak pemasaran hasilpertanian. Masyarakat sekitar biasanya hanya memasarkan ke kota dengan harga yang tidak banyak menguntungkan. Masyarakat hanya menjual pisang berupa buah tidak berupa olahan pisang. Padahal jika masyarakat dapat mengolah buah pisang menjadi olahan khas akan menambah pendapatan masyarakat.

Nugget merupakan makanan fast food yang biasanya digemari oleh berbagai kalangan karena rasanya enak dan cara memasaknya yang mudah. Nugget biasanya terbuat dari daging ayam dengan tekstur lembut dan rasanya pun gurih. Berbeda dengan nugget pisang, karena terbuat daripisang maka teksturnya tetap lembut dengan rasa manis dan rasa khas pisang tersebut.

Nugget yang terbuat dari pisang ini dijamin sehat dan aman untuk dikonsumsi sehari-hari oleh masyarakat. Factor yang mempengaruhi mutu nugget pisang adalah tingkat keasaman pada pisang, tekstur kelembutan pisang, dan tepung yang dicampurkan. Usaha nugget pisang dapat dikembangkan di Desa Donowangun karena produksi pisang yang cukup melimpah.

Desa Donowangun merupakan salah satu desa di kecamatan Talun, Kabupaten Pekalongan, Jawa Tengah. Luas wilayah Desa Donowangun sebesar 443.000 Ha. Jumlah penduduk Desa Donowangun sendiri sebanyak 
4.490 Jiwa yang terdiri dari 2.082 laki-laki dan 2.408 perempuan. Desa Donowangun memiliki batas-batas administratif yaitu sebelah utara berbatasan dengan Desa Talun, sebelah selatan berbatasan dengan Desa Jolotigo, dan untuk dibagian timur berbatasan dengan Desa Batursari dan Desa Sengare, sedangkan dibagian barat berbatasan dengan Desa Talun dan Desa Mesoyi.

Dilihat dari topografi dan kontur tanah, Desa Donowangun Kecaamatan Talun secara umum berupa Persawahan dan Perbukitan yang berada pada ketinggian antara $90 \mathrm{~m} \mathrm{~s} / \mathrm{d} 100 \mathrm{~m}$ di atas permukaan laut dengan suhu ratarata berkisar antara $29^{\circ} \mathrm{s} / \mathrm{d} 30^{\circ}$ Celcius. Desa Donowangun terdiri dari 6 (Enam) Dusun, 3 (Tiga) RW dan 20 (Duapuluh) RT. Waktu tempuhdari ibukota kecamatan $8 \mathrm{~km}^{2}$ dengan waktu tempuh 20 menit dan dari ibukota kabupaten $34 \mathrm{~km}^{2}$ dengan waktu tempuh 90 menit.

Pendidikan sendiri di Desa Donowangun sudah cukup memadai karena sudah memiliki 2 SD Negeri, 3 MI, 1 MTs dan juga memiliki SMK yang berada di Desa Donowangun sendiri. Masyarakat Desa Donowangun sebagian besar memiliki mata pencaharian sebagai petani hampir 90\% dibandingkan dengan pekerjaan yang lain seperti PNS dan karyawan swasta. ${ }^{1}$

\section{Metode}

Pelaksanaan kegiatan pelatihan pengolahan Pisang nugget dalam mengatasi persoalan pada kelompok masyarakat yang belum mandiri ekonomi ialah dengan melakukan penyuluhan, pelatihan teknis dan pendampingan melalui berbagai pendekata. Pendekatanb yang digunakan ialah pendekatan kelompok dan pendekatan individu. Pendekatan kelompok dilakukan pada saat pemberian penyuluhan mengenai pemanfaatan buah

\footnotetext{
${ }^{1}$ Desa Donowangun. https://id.wikipedia.org/wiki/Donowangun,Talun, Pekalongan.
} 
pisang dan pelatihan pengolahan pisang nugget. Sedangkan untuk pendekatan individu dilakukan pada saat diskusi dan tanya jawab dengan peserta pelatihan secara intensif. Adapun metode yang digunakan ialah :

\section{1) Ceramah Kreatif}

Menurut KBBI ceramah adalah pidato yang bertujuan untuk memberikan nasehat dan petunjuk-petunjuk, sementara audiensi yang bertindak sebagai pendengar. Ceramah kreatifpada metode ini, narasumber memberikan materi dengan berbagai kreativitas yang dimiliki sehingga audiensi dapat menyerap materi dengan baik dan tidak merasakan bosan ataupun tidak memperhatikan narasumber. Dengan metode ceramah kreatif, audiensi mendapatkan kaeuntungan karena narasumber dituntut untuk menyampaikan materi dengan detail sehingga materi tesampaikan dengan baik.

\section{2) Praktek/Demonstrasi}

Praktek dilakukan ketika materi telah tersampaikan dengan baik. Praktek/demonstrasi pembuatan pisang nugget dilakukan oleh narasumber dibantu dengan tim. Audiensi bisa menyaksikan dengan jelas dan boleh mengajukan pertanyaan ketika pertengahan praktek ada hal yang tidak dipahami. Selain itu, audiensi juga diperbolehkan mendekat untuk menyaksikan pengolahan buah pisang menjadi pisang nugget.

\section{3) Diskusi}

Diskusi dilakukan pada saat pelatihan berlangsung dan setelah pelatihan selesai. Dalam sesi ini, tim berusaha untuk melakukan pendampingan secara individu agar individu semakin mengerti sehingga nantinya akan didapat keluaran yang sesuai dengan harapan. 


\section{Hasil Dan Diskusi}

Kegiatan pelatihan pengolahan pisang nugget ini dimulai dengan pembukaan dan memberikan materi pendahuluan mengenai potensi buah pisang di Desa Donowangun yang melimpah. Metode yang digunakan yaitu ceramah kreatif dan demonstrasi (praktek). Kemudian menjelaskan materi tentang pangsa pasar dan prospek olahan buah pisang yang lebih berinovasi dari pada hanya sekedar digoreng seperti biasa. Pelaksanaan sosislisasi tersebut dilakukan secara bertahap dari satu dusun ke dusun yang lain melalui kegiatan yang dilakukan oleh ibu-ibu PKK yaitu seperti pengajian/nariyahan/minggu sehat di Desa Donowangun. Sosialisasi pengolahan pisang nugget itu sendiri dilaksanakan pada minggu ke-3 diawali di dusun Bangun kidul.

Dalam pelaksanaan kegiatan pelatihan pengolahan buah pisang di Desa Donowangun ini sebagian besar diikuti oleh para ibu-ibu PKK yang sangat berantusias dan penasaran terhadap kegiatan pelatihan tersebut terutama terhadap produk atau hasil dari pelatihannya tersebut, karena pisang nugget masih terbilang sangat jarang ditemukan di sekitar Desa Donowangun bahkan di Kecamatan Talun sendiri. Kegiatan pelatihan ini para ibu-ibu PKK tidak hanya berperan sebagai penonton akan tetapi mereka juga diberi kesempatan untuk mencoba/praktek membuat pisang nugget tersebut dengan dibimbing oleh para Mahasiswa KKN. Pada saat ibu-ibu praktek membuat pisang nugget tersebut tidak hanya dilakukan oleh satu orang akan tetapi dilakukan secara bergiliran dimana hal ini bertujuan agar semua ibuibu merasakan membuat pisang nugget tidak hanya satu orang yang melakukan praktek.

Sebelum melakukan praktek pengolahan buah pisang menjadi pisang nugget, ibu-ibu hanya mengolahnya dengan cara digoreng, dibuat kolak pisang maupun makan seperti biasa sehingga dengan adanya pelatihan 
tersebut yang nantinya dapat menghasilkan produk terbaru yaitu pisang nugget dan jika ibu-ibu dapat menekuni dan meneruskan resep pisang nugget tersebut maka dapat berpeluang sebagai usaha rumahan atau home industri yang dapat membawa perekonomian Desa Donowangun.

Selain melakukan pelatihan dalam mengolah buah pisang, para ibu-ibu PKK juga diajarkan mengenai pengemasan setelah menjadi pisang nugget sehingga dapat ,menarik minat para pembeli selain itu juga dapat membuat pisang nugget tersebut terkesan lebih bagus dan lebih berkelas jika dibandingkan hanya dibungkus menggunakan plastik biasa, apalagi jika pisang nugget tersebut dipasarkan di luar Desa Donowangun akan dapat menjadi identitas atau ciri khas dari Desa Donowangun sendiri.

\section{Simpulan}

Program kegiatan KKN UNNES tahun 2018 "Pengolahan Buah Pisang Menjadi Pinangun (Pisang Nugget Donowangun) Sebagai Upaya Peningkatan Pendapatan Masyarakat Desa Donowangun" berhasil dengan baik. Antusiasme ibu-ibu PKK sebagai peserta penyuluhan cukup baik. Kegiatan pelatihan ini menambah wawasan audiensi mengenai pemanfaatan buah pisang. Buah pisang selain bisa dijadikan sebagai pisang goreng juga bisa diolah menjadi pisang nugget guna menambah nilai ekonomis dari buah pisang itu sendiri.

Kegiatan pelatihan ini dilaksanakan secara berkelanjutan dan diharapkan kedepannya ada Dinas terkait yang mau memberikan pendampingan mengenai perijinan usaha. Selain itu, diharapkan ibu-ibu PKK Desa Donowangun dapat mengikuti kegiatan pelatihan-pelatihan lainnya. 


\section{Referensi}

Departemen Pertanian. (1983). Pedoman Bercocok Tanam Padi, Palawija, Sayur- sayuran dan Buah-buahan. Satuan Pengendali Bimas:Jakarta.

Moekiyat. (1991). Latihan dan Pengembangan Sumber Daya Manusia. Bandung: Mandar Maju.

Notoadmodjo. S. (1992). Pengembangan Sumber Daya Manusia. Jakarta: Rineke Cipta.

Sartono. (1990). Pokok Dalam Pembangunan Masyarakat Desa. Bandung.

Soekanto. S, (1970). Sosiologi Suatu Pengantar. Jakarta: Yayasan Penerbit Universitas Indonesia.

Jurnal Holistik, Tahun IX No. 17A/ Januari - Juni 2016.

Wikipedia.(2018). Buah Pisang. https://id.wikipedia.org/wiki/Pisang. diakses, 29 November 2018.

Wikipedia. (2016). Profil Desa Donowangun. https://id.wikipedia.org/wiki/Donowangun,_Talun,_Pekalongan.

Diakses, 29 November 2018. 